\title{
EFEITO DE SISTEMAS DE PRODUÇÃO E DOSES DE ADUBO DE LIBERAÇÃO LENTA NO ESTADO NUTRICIONAL DE PORTA-ENXERTO CÍTRICO ${ }^{1}$
}

\author{
LUIZ AUGUSTO LOPES SERRANO², CLÁUDIA SALES MARINHO³, ALMY JÚNIOR CORDEIRO DE CARVALHO, \\ PEDRO HENRIQUE MONNERAT ${ }^{3}$
}

\begin{abstract}
RESUMO - O sistema de produção do porta-enxerto, antes da repicagem, pode modificar o sistema radicular das plântulas e a resposta destas à adubação. Assim, o objetivo desse trabalho foi avaliar os efeitos de três sistemas de produção do limoeiro 'Cravo' e de cinco doses de um adubo de liberação lenta, aplicados após a repicagem, sobre o estado nutricional do limoeiro 'Cravo' no ponto de enxertia. O experimento foi conduzido, sob viveiro telado, em esquema fatorial 3 x 5, com sete repetições e uma planta por parcela. Os sistemas de produção do porta-enxerto foram: 1- produção em tubetes e citrovasos preenchidos com substrato comercial composto por casca de pínus; 2- produção em tubetes e citrovasos preenchidos com substrato composto por bagaço de cana-de-açúcar + torta de filtro (3:2; v:v), e 3- produção em blocos prensados e citrovasos constituídos pela prensagem do substrato utilizado no sistema 2. As doses de adubo de liberação lenta, fórmula NPK 14-14-14, foram: 5; $10 ; 15 ; 20$ e 25 g/planta. O sistema de produção do porta-enxerto, antes da repicagem, influenciou na resposta do limoeiro 'Cravo' à adubação após a repicagem. No ponto de enxertia, as plantas cultivadas no sistema de blocos prensados apresentaram menores teores foliares de $\mathrm{P}, \mathrm{K}$ e Fe em relação às plantas provenientes de tubetes, mas apresentaram maiores médias de crescimento (peso seco do sistema radicular, peso seco de folhas, peso seco de caules e diâmetro do caule). Plantas cultivadas no sistema 1 apresentaram sintomas foliares de deficiência de Fe, enquanto as plantas dos outros dois sistemas apresentaram sintomas foliares de deficiência de $\mathrm{Mg}$.
\end{abstract}

Termos para indexação: Citrus limonia, propagação, substratos, deficiência de ferro, deficiência de magnésio.

\section{THE EFFECT OF PRODUCTION SYSTEMS AND DOSES OF CONTROLLED-RELEASE FERTILIZER ON THE NUTRITIONAL STATUS OF CITRUS ROOTSTOCK}

\begin{abstract}
The production system of citrus rootstock before the transplanting can modify the seedlings root system and the response of these to fertilization. The objective of this experiment was to evaluate the effects of three production systems of 'Rangpur' lime tree and five doses of a controlled-release fertilizer, applied after transplanting, on the nutritional status of rootstock in the grafting point. The experiment was carried out, under a screen-protected nursery, in a factorial scheme $3 \times 5$, with seven replicates and one plant per experimental plot. The production systems of citrus rootstock were: 1 - production in stiff plastic tubes filled up with commercial substrate constituted of pinus bark; 2 - production in stiff plastic tubes filled up with substrate constituted of industrial residues of the region, that is, sugarcane bagasse + industrial sugarcane plant residues, (3:2; $\mathrm{v}: \mathrm{v})$; and 3 - production in pressed blocks constituted of the pressed substrate used in system 2 . The five doses of controlled-release fertilizer formula NPK 14-14-14 were 5, 10, 15, 20 and $25 \mathrm{~g} /$ plant. The production system of citrus rootstock before transplanting, influenced the plant response to the fertilization after transplanting. In the grafting point, the plants grown under the pressed block system presented smaller contents of $\mathrm{P}$, K, and Fe in comparison to plants under grown in stiff plastic tubes system, but presented larger growth (root system dry matter, leaf dry matter, stem dry matter and stem diameter). Plants grown in system 1 presented iron deficiency symptoms in leaves, while plants from the other two systems presented magnesium deficiency symptoms in leaves.
\end{abstract}

Index terms: Citrus limonia, propagation, substrate, iron deficiency, magnesium deficiency.

\section{INTRODUÇÃO}

As mudas cítricas certificadas devem ser produzidas em sistemas protegidos e com o uso de substratos isentos de patógenos e adequados a esse sistema (Carvalho, 2001). O emprego de recipientes com dimensões limitadas e o longo período de permanência dessas plantas nestes recipientes tornam o sistema radicular sujeito a restrições físicas (Rezende et al., 2002) e a adubação um fator decisivo para o bom desenvolvimento das mudas (Perin et al., 1999).

Uma alternativa ao uso de tubetes, na primeira fase de produção do porta-enxerto cítrico, é a utilização do sistema de blocos prensados, no qual o substrato prensado constitui um recipiente natural para a muda. Esses blocos são fertilizados durante sua confecção e colocados em caixas plásticas com fundos telados, para promover a poda natural das raízes. Pesquisas com mudas de eucalipto têm demonstrado que a poda do sistema radicular exerce um efeito positivo, aumentando a ramificação, o número de extremidades de novas raízes e o peso seco do sistema radicular, além de promover maior precocidade na formação de mudas quando comparadas à produção em tubetes ou em bandejas de isopor (Morgado, 1998; Barroso, 1999).

Os fertilizantes de liberação lenta, em suas diversas formulações e recomendações, são de grande praticidade para a produção de mudas em recipientes. A premissa básica para o uso dos adubos de liberação lenta é a liberação contínua dos nutrientes, reduzindo a possibilidade de perdas por lixiviação e mantendo a planta nutrida constantemente durante todo o período de crescimento. O seu uso apresenta outras inúmeras vantagens, tais como: a redução da mão-de-obra para adubações em cobertura; a redução da perda de nitrogênio por volatilização da amônia; a redução dos danos na semente ou nas plântulas pela salinidade do meio de cultivo, entre outras (Sharma, 1979). Entretanto, o uso de diferentes substratos requer a calibração de doses do fertilizante para atender de forma equilibrada à demanda nutricional da muda cítrica.

O sistema de produção do porta-enxerto, antes da repicagem, pode modificar o sistema radicular das plântulas e a resposta destas à adubação. Assim, o objetivo deste trabalho foi avaliar os efeitos de três sistemas de produção do porta-enxerto e de cinco doses de um adubo de liberação lenta, aplicados após a repicagem, sobre o estado nutricional do limoeiro 'Cravo' na época da enxertia.

\section{MATERIAL E MÉTODOS}

O experimento foi conduzido sob viveiro telado, na Universidade Estadual do Norte Fluminense, em Campos dos Goytacazes - RJ, entre julho de 2001 e março de 2002. Adotou-se o delineamento inteiramente

\footnotetext{
' (Trabalho 065/2004). Recebido: 02/06/2004. Aceito para publicação: 28/10/2004. Parte da dissertação de Mestrado do primeiro autor apresentada à Universidade Estadual do Norte Fluminense 'Darcy Ribeiro' - UENF.

${ }^{2}$ Eng. ${ }^{\circ}$ Agr ${ }^{\circ}$, M.Sc., Doutorando, Bolsista CNPq, UENF/CCTA/LFIT, Av. Alberto Lamego 2000, Horto, 28015-620, Campos dos Goytacazes-RJ, serrano@ uenf.br. ${ }^{3}$ Eng. $^{\circ}$ Agr ${ }^{\circ}$, D.Sc., Professores, UENF/CCTA/LFIT, Av. Alberto Lamego 2000, Horto, 28015-620, Campos dos Goytacazes-RJ, marinho@ uenf.br. Apoio Financeiro: FENORTE, CNPq.
} 
TABELA 1 - Composição química dos substratos utilizados para a produção do porta-enxerto limoeiro 'Cravo'. UENF, Campos dos Goytacazes-RJ, 2001.

\begin{tabular}{|c|c|c|c|c|c|c|c|c|c|c|c|c|}
\hline \multirow[t]{2}{*}{ Substratos $^{1}$} & \multirow{2}{*}{$\begin{array}{c}\mathrm{pH} \\
\left(\mathrm{H}_{2} \mathrm{O}\right)\end{array}$} & $\mathbf{N}$ & $\mathbf{P}$ & $\mathbf{K}$ & Ca & Mg & $\mathbf{S}$ & C & \multirow{2}{*}{\multicolumn{4}{|c|}{$\frac{\mathrm{Cu} \quad \mathrm{Zn}}{\mathrm{mg} \mathrm{kg}^{-1}}$}} \\
\hline & & & & & $\mathrm{g} \mathrm{kg}^{-1}$ & & & & & & & \\
\hline $\begin{array}{l}\text { Comercial } \\
\text { (Casca de pínus moída) }\end{array}$ & 5,2 & 10,6 & 13,8 & 4,9 & 23,4 & 20,4 & 3,5 & 463 & 5.640 & 24 & 40 & 205 \\
\hline $\mathrm{BC}+\mathrm{TF}(3: 2 ; \mathrm{v}: \mathrm{v})$ & 6,5 & 18,2 & 27,9 & 2,4 & 48,0 & 4,9 & 6,7 & 288 & 15.600 & 88 & 206 & 860 \\
\hline
\end{tabular}

(1) BC: bagaço de cana-de-açúcar; TF: torta de filtro.

casualizado, em esquema fatorial (3x5), com sete repetições e uma planta por parcela. Os sistemas de produção do porta-enxerto até a repicagem foram: 1- produção em tubetes preenchidos com substrato comercial composto por casca de pínus moída; 2- produção em tubetes preenchidos com substrato composto por bagaço de cana-de-açúcar + torta de filtro, (3:2; v:v), e 3- produção em blocos prensados confeccionados com substrato composto por bagaço de cana-de-açúcar + torta de filtro $(3: 2$; $\mathrm{v}: \mathrm{v})$.

$\mathrm{Na}$ repicagem, as plantas foram replantadas em citrovasos preenchidos, respectivamente, com os mesmos substratos utilizados na fase anterior, fertilizados com 5 doses de adubo de liberação lenta (Osmocote $\left.{ }^{\circledR} 14-14-14\right): 5 ; 10 ; 15 ; 20$ e $25 \mathrm{~g} /$ planta $(1,32 ; 2,64 ; 3,96 ; 5,28 \mathrm{e}$ $6,60 \mathrm{~kg} \mathrm{~m}^{-3}$ de substrato). Este adubo é composto pelos seguintes sais: nitrato de amônio $(32 \% \mathrm{~N})$, fosfato de amônio $\left(11 \% \mathrm{~N}\right.$ e $52 \%$ de $\left.\mathrm{P}_{2} \mathrm{O}_{5}\right)$, fosfato bicálcico ( $31 \%$ de $\mathrm{P}_{2} \mathrm{O}_{5}$ e $20 \%$ de Ca) e sulfato de potássio $(48 \%$ de $\mathrm{K}_{2} \mathrm{O}, 16 \%$ de $\mathrm{S}$ e $0 \mathrm{a} 1,2 \%$ de $\mathrm{Mg}$ ). Em relação à concentração total de $\mathrm{N}$, têm-se $5,8 \%$ na forma nítrica e $8,2 \%$ na forma amoniacal.

$\mathrm{O}$ ponto de repicagem foi estipulado para quando todas as plantas do experimento atingissem altura média de $10 \mathrm{~cm}$ a partir do colo das plantas. O ponto de enxertia foi determinado quando as plantas do experimento atingiram a média de diâmetro do caule de $8 \mathrm{~mm}$, medido aos $10 \mathrm{~cm}$ do colo. Utilizaram-se régua e paquímetro digital para estas medições.

Os blocos prensados após o início das irrigações diárias tinham 0,6 m de comprimento, 0,4 m de largura e 0,1 m de altura. Possuíam 96 pontos de semeadura igualmente distribuídos e foram colocados em caixas de madeira com fundos telados. Os tubetes e os citrovasos utilizados tinham capacidade de $50 \mathrm{~cm}^{3}$ e $3,8 \mathrm{dm}^{3}$, respectivamente. Semearam-se três sementes por célula, havendo extração manual do tegumento externo (testa) das sementes.

As análises químicas dos substratos utilizados (Tabela 1) foram realizadas pelo Laboratório de Análises de Solos da UFRRJ em Campos dos Goytacazes. As amostras foram submetidas às digestões sulfúrica, para a determinação do $\mathrm{N}$ total, e nitríco-perclórica, para determinação de $\mathrm{P}, \mathrm{K}, \mathrm{Ca}, \mathrm{Mg}, \mathrm{S}, \mathrm{Fe}, \mathrm{Cu}, \mathrm{Zn}, \mathrm{Mn}$ e Na por espectrofotometria. $\mathrm{O} \mathrm{Cl}$ foi determinado em água por espectrofotometria e o C da matéria orgânica pelo método volumétrico, utilizando-se do bicromato de potássio.

$\mathrm{Na}$ fase de semeadura, adicionaram-se aos substratos $300 \mathrm{~g} \mathrm{~m}^{-}$ ${ }^{3}$ de Osmocote ${ }^{\circledR} 14-14-14$. Aos 20 dias após a germinação, iniciaram-se pulverizações foliares com solução de $6 \mathrm{~g} \mathrm{~L}^{-1}$ de uréia, sendo repetidas em intervalos de 10 dias até o ponto de repicagem.

$\mathrm{Na}$ repicagem (73 dias após a semeadura), foram misturados aos substratos 2,0 $\mathrm{kg} \mathrm{m}^{-3}$ de superfosfato simples $\left(364 \mathrm{~g} \mathrm{~m}^{-3} \mathrm{de}_{2} \mathrm{O}_{5}\right)$ e as cinco doses do adubo de liberação lenta. Também houve o início das pulverizações mensais com solução composta por: $1 \mathrm{~g} \mathrm{~L}^{-1}$ de oxicloreto de cobre; $1 \mathrm{~g} \mathrm{~L}^{-1}$ de ácido bórico; $4 \mathrm{~g} \mathrm{~L}^{-1}$ de sulfato de magnésio; $3,5 \mathrm{~g} \mathrm{~L}$ ${ }^{1}$ de sulfato de zinco; $2,5 \mathrm{~g} \mathrm{~L}^{-1}$ de sulfato de manganês, e 5,0 $\mathrm{g} \mathrm{L}^{-1}$ de uréia. Na primeira pulverização, houve a adição de $0,2 \mathrm{~g} \mathrm{~L}^{-1}$ de molibdato de sódio. Utilizou-se para aplicação da calda um pulverizador costal manual, sendo aplicado um volume de calda que molhasse por completo as páginas abaxial e adaxial de todas as folhas das plantas.

As plantas cultivadas em tubetes preenchidos com substrato comercial (sistema 1) apresentaram, aos 50 dias após a repicagem, sintomas de deficiência de Fe, com início nas folhas mais jovens, seguidos de uma severa redução em seu crescimento. Então, foram realizadas três pulverizações mensais com sulfato ferroso $\left(1,0 \mathrm{~g} \mathrm{~L}^{-1}\right)$.
Constatado o ponto de enxertia (154 dias após a repicagem), foram medidos a altura e o diâmetro do caule das plantas. Após a medição, realizaram-se o corte da parte aérea, rente ao colo, e a separação das raízes dos substratos, utilizando-se de água corrente. As folhas foram separadas dos caules para a avaliação da área foliar no aparelho LI-3100 area meter ${ }^{\circledR}$. As folhas, os caules e as raízes foram colocados para secar em estufa $\left(70{ }^{\circ} \mathrm{C}\right.$ por $\left.72 \mathrm{~h}\right)$ para posterior determinação, por gravimetria, dos pesos secos do sistema radicular, das folhas e dos caules.

Após a pesagem, as folhas foram trituradas em moinho tipo Willey, para que, então, fossem submetidas a análises químicas para determinação de N, P, K, Ca, Mg, S, B, Fe, Mn e Zn. Após o material vegetal das amostras ter sido oxidado pela digestão nítrico-perclórica, os teores de $\mathrm{Ca}, \mathrm{Mg}, \mathrm{Fe}, \mathrm{Mn}$ e $\mathrm{Zn}$ foram quantificados por espectrofotometria de absorção atômica, o teor de $\mathrm{K}$ por espectrofotometria de emissão de chama, o teor de $\mathrm{S}$ por turbidimetria do sulfato e o teor de $\mathrm{P}$ foi quantificado colorimetricamente pelo método do molibdato. $\mathrm{O}$ teor de $\mathrm{N}$ foi determinado pelo método de Nessler, após submeter o material vegetal à oxidação pela digestão sulfúrica. O B foi determinado colorimetricamente pela azometina-H após incineração do material vegetal em mufla.

As médias de crescimento e dos teores foliares foram submetidas a análises de variância. Os sistemas de produção foram comparados pelo teste de Tukey e as doses de adubo foram submetidas a análises de regressão, adotando-se o nível de 5\% de significância para ambos os casos.

\section{RESULTADOS E DISCUSSÃO}

Não houve interação entre os sistemas de produção das mudas e as doses de adubo aplicadas para os teores médios de N, Ca, S, Mn e $\mathrm{Zn}$ na matéria seca foliar das plantas provenientes dos três sistemas (Figuras 1A, 1B, 1C, 1D e 1E); entretanto, o incremento da adubação promoveu resposta linear crescente para os teores de N, S, Mn e Zn e resposta quadrática para os teores de $\mathrm{Ca}$, com máximo teor obtido na dose de $15,9 \mathrm{~g} /$ planta.

Para os demais nutrientes avaliados, foi observada interação entre os sistemas de produção das mudas e as doses de adubo aplicadas. As plantas provenientes do sistema 3 apresentaram respostas lineares crescentes dos teores de P, Ke B (Figuras 1F, 1G e 1I) e nenhuma variação nos teores de $\mathrm{Mg}$ (Figura $1 \mathrm{H}$ ). Para o $\mathrm{Mg}$, foi observado um efeito quadrático da adubação sobre os teores foliares das plantas do sistema 1 e nenhuma variação nos teores das plantas do sistema 2 (Figura $1 \mathrm{H}$ ). As plantas dos sistemas 1 e 2 apresentaram respostas quadráticas à adubação para os teores foliares de $\mathrm{Pe} \mathrm{K}$ (Figura $1 \mathrm{Fe} 1 \mathrm{G}$ ), sendo os mais altos teores de $\mathrm{P}$ correspondentes às doses de 21,2 e 15,5 g/planta, respectivamente. Nestes sistemas, não foram observadas variações nos teores de B em função da adubação empregada (Figura 1I).

As plantas provenientes dos sistemas que utilizaram o substrato composto por bagaço de cana-de-açúcar + torta de filtro, em tubetes ou nos blocos prensados (sistemas 2 e 3), apresentaram médias de área foliar, peso seco do sistema radicular, peso seco das folhas, peso seco dos caules, altura das plantas e diâmetro do caule superiores aos das plantas cultivadas em tubetes com substrato comercial (Tabela 2). Resultados semelhantes foram encontrados por Morgado (1998) e Barroso (1999) ao utilizarem este substrato para a produção de mudas de cana-de-açúcar e de eucalipto. Os pesos secos do sistema radicular, das 

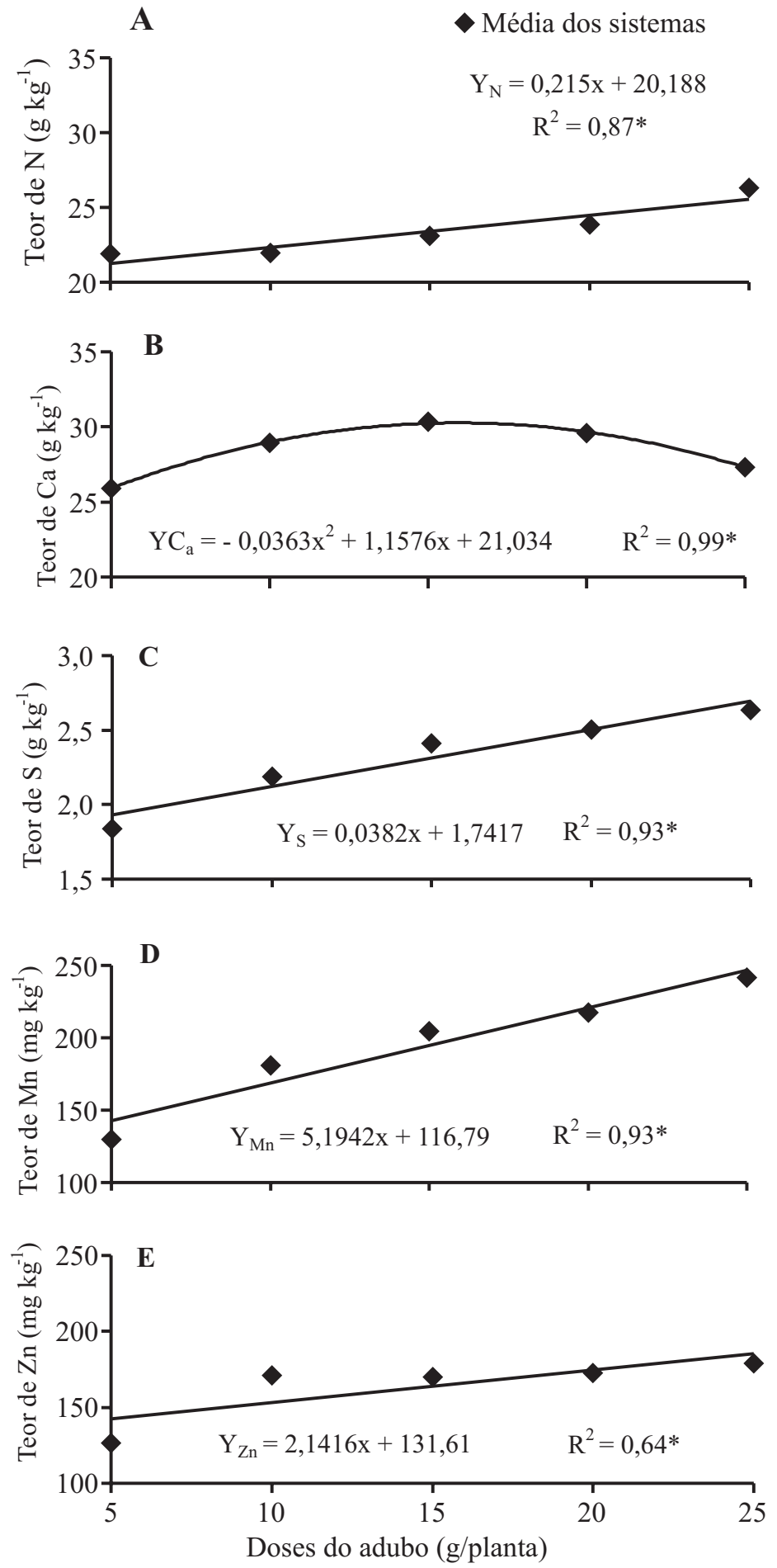

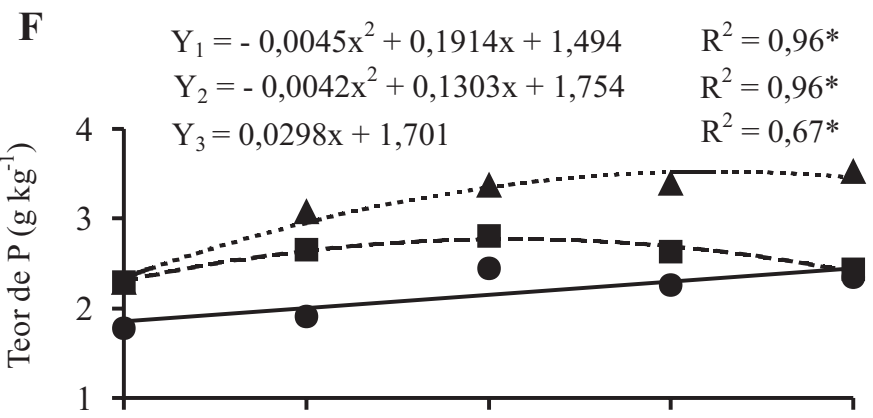

G
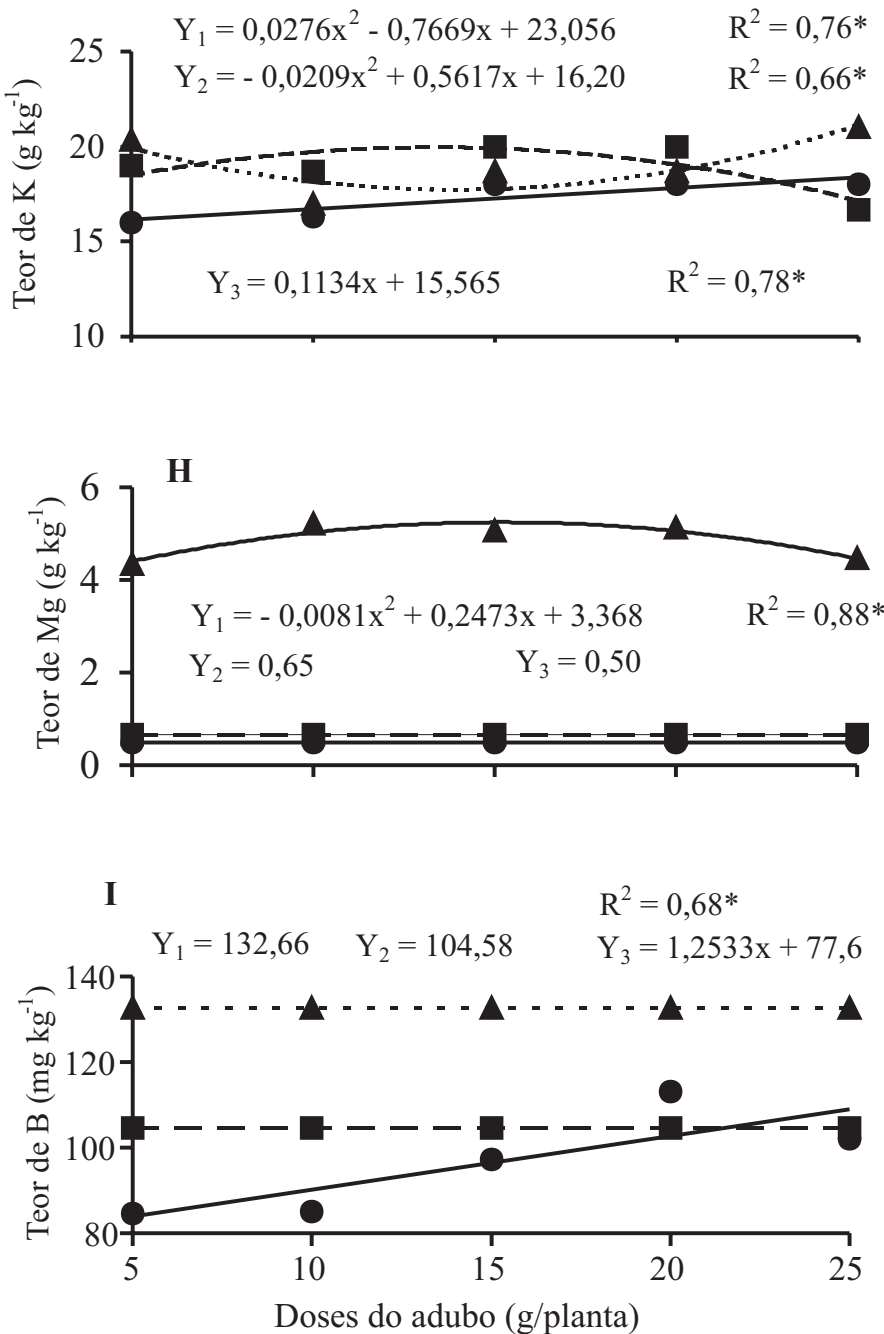

FIGURA 1 - Teores foliares médios de N (A), Ca (B), S (C), Mn (D), Zn (E), P(F), K (G), Mg (H) e B (I), em limoeiro 'Cravo', no ponto de enxertia, em função de cinco doses de adubo de liberação lenta, fórmula NPK 14-14-14, em três sistemas de produção de porta-enxerto ( $\Delta$-sistema 1; --sistema 2 e •-sistema 3). UENF, Campos dos Goytacazes-RJ, 2002.

folhas e dos caules, assim como o diâmetro do caule das mudas provenientes do sistema de blocos prensados, foram superiores aos das plantas provenientes de tubetes (sistemas 1 e 2), proporcionando maior precocidade na formação do porta-enxerto, visto que estes atingiram o diâmetro do caule estipulado para a prática de enxertia em menos tempo (137 dias após a repicagem).

Em média, os teores de $\mathrm{N}, \mathrm{P}$ e $\mathrm{K}$ das plantas provenientes do sistema de blocos prensados foram inferiores aos das plantas cultivadas em tubetes preenchidos com substrato comercial (Tabela 3 ), o que pode ser decorrente da diferença de crescimento observada entre essas plantas (Tabela 2). Segundo Malavolta et al. (1997), diferentes respostas em crescimento podem provocar alterações nas concentrações dos nutrientes, pelo chamado efeito de diluição ou concentração.

O maior crescimento das plantas provenientes do sistema 3 pode ter aumentado a demanda por $\mathrm{P}$ e $\mathrm{K}$ pelas plantas, e, para estas, quantidades acima das doses do adubo empregadas poderiam resultar em teores foliares mais altos desses nutrientes.

As plantas provenientes dos sistemas que utilizaram o substrato composto por bagaço de cana-de-açúcar + torta de filtro (sistemas 2 e 3), apresentaram teores foliares de Ca cerca de $30 \%$ superiores aos das plantas cultivadas em substrato comercial (Tabela 3 ). Estes valores superiores podem ser atribuídos à composição química do substrato utilizado nestes sistemas (Tabela 1) e corroboram a afirmação de Leme (1993) de que a torta de filtro é uma excelente fonte de cálcio.

Em contrapartida, os teores de $\mathrm{Mg}$ nas plantas do sistema 1 foram cerca de oito vezes maiores que os das plantas dos sistemas 2 e 3 (Tabela 3). Além de mais baixos, esses teores apresentaram-se abaixo do ponto inferior da faixa adequada $\left(0,7\right.$ a $\left.5,2 \mathrm{~g} \mathrm{~kg}^{-1} \mathrm{de} \mathrm{Mg}\right)$ apresentada por Vichiato (1996) para esse porta-enxerto. Nessas plantas, foram observados sintomas visuais de deficiência de $\mathrm{Mg}$ nas folhas inferiores. 
TABELA 2 - Valores médios para área foliar (AF), peso seco do sistema radicular (PSSR), peso seco das folhas (PSF), peso seco dos caules (PSC), diâmetro do caule (DC) e altura (ALT) de plantas de limoeiro 'Cravo' no ponto de enxertia, produzidas em três sistemas de produção de porta-enxerto sob cinco doses de adubo de liberação lenta, fórmula NPK 14-14-14. UENF, Campos dos Goytacazes-RJ, 2002.

\begin{tabular}{ccccccc}
\hline Sistemas & AF $\left(\mathbf{c m}^{2}\right)$ & PSSR $(\mathbf{g})$ & PSF $(\mathbf{g})$ & PSC $(\mathbf{g})$ & DC $(\mathbf{m m})$ & ALT $(\mathbf{c m})$ \\
\hline $\mathbf{1}$ & $911,7 \mathrm{~b}$ & $7,8 \mathrm{c}$ & $6,8 \mathrm{c}$ & $8,7 \mathrm{c}$ & $6,8 \mathrm{c}$ & $79,7 \mathrm{~b}$ \\
$\mathbf{2}$ & $1.846,6 \mathrm{a}$ & $10,5 \mathrm{~b}$ & $15,8 \mathrm{~b}$ & $16,9 \mathrm{~b}$ & $8,3 \mathrm{~b}$ & $131,4 \mathrm{a}$ \\
$\mathbf{3}$ & $1.926,4 \mathrm{a}$ & $15,5 \mathrm{a}$ & $18,3 \mathrm{a}$ & $20,2 \mathrm{a}$ & $9,1 \mathrm{a}$ & $133,8 \mathrm{a}$ \\
\hline Média Geral & $1.561,5$ & 11,3 & 13,6 & 15,2 & 8,1 & 114,9 \\
dms & 178,3 & 1,7 & 1,7 & 2,5 & 0,4 & 7,7 \\
Cv (\%) & 20,0 & 26,1 & 22,5 & 28,8 & 9,0 & 11,8 \\
\hline
\end{tabular}

Médias na coluna, seguidas por letras diferentes, são diferentes em nível de 5\% de probabilidade, pelo teste de Tukey.

TABELA 3 - Teores médios de macronutrientes $\left(\mathrm{g} \mathrm{kg}^{-1}\right)$ e micronutrientes $\left(\mathrm{mg} \mathrm{kg}^{-1}\right)$ na matéria seca foliar de plantas de limoeiro 'Cravo' no ponto de enxertia, produzidas em três sistemas de produção de porta-enxerto sob cinco doses de adubo de liberação lenta, fórmula NPK 14-14-14. UENF, Campos dos Goytacazes-RJ, 2002.

\begin{tabular}{ccccccccccc}
\hline Sistemas & $\mathbf{N}$ & $\mathbf{P}$ & $\mathbf{K}$ & $\mathbf{S}$ & $\mathbf{C a}$ & $\mathbf{M g}$ & $\mathbf{M n}$ & $\mathbf{Z n}$ & $\mathbf{B}$ & $\mathbf{F e}$ \\
\hline $\mathbf{1}$ & $25,3 \mathrm{a}$ & $3,1 \mathrm{a}$ & $19,1 \mathrm{a}$ & $2,1 \mathrm{~b}$ & $22,0 \mathrm{c}$ & $4,8 \mathrm{a}$ & $157,4 \mathrm{~b}$ & $140,6 \mathrm{~b}$ & $132,6 \mathrm{a}$ & $328,5 \mathrm{a}$ \\
$\mathbf{2}$ & $23,5 \mathrm{ab}$ & $2,6 \mathrm{~b}$ & $18,9 \mathrm{a}$ & $2,4 \mathrm{a}$ & $33,1 \mathrm{a}$ & $0,6 \mathrm{~b}$ & $218,7 \mathrm{a}$ & $183,0 \mathrm{a}$ & $104,6 \mathrm{~b}$ & $146,9 \mathrm{~b}$ \\
$\mathbf{3}$ & $21,4 \mathrm{~b}$ & $2,1 \mathrm{c}$ & $17,3 \mathrm{~b}$ & $2,4 \mathrm{a}$ & $30,1 \mathrm{~b}$ & $0,5 \mathrm{~b}$ & $208,0 \mathrm{a}$ & $167,6 \mathrm{ab}$ & $96,4 \mathrm{~b}$ & $106,3 \mathrm{c}$ \\
\hline Média Geral & 23,4 & 2,6 & 18,4 & 2,3 & 28,4 & 2,0 & 194,7 & 163,8 & 111,2 & 193,9 \\
dms & 2,3 & 0,2 & 1,3 & 0,2 & 2,1 & 0,2 & 36,8 & 29,4 & 11,6 & 34,9 \\
Cv (\%) & 10,9 & 8,7 & 7,68 & 9,7 & 8,4 & 12,7 & 21,0 & 19,9 & 11,6 & 20,0 \\
\hline
\end{tabular}

Médias na coluna, seguidas por letras diferentes, são diferentes em nível de 5\% de probabilidade, pelo teste de Tukey.

No sistema 2, as plantas que receberam as doses de 5 e $10 \mathrm{~g} / \mathrm{planta}$, apresentaram teores dentro da faixa citada, mas também apresentaram sintomas de deficiência de $\mathrm{Mg}$.

Segundo Lopes (1998), a deficiência de Mg pode ser acentuada pela aplicação de altas doses de $\mathrm{K}$ e de $\mathrm{NH}_{4}^{+}$ao substrato, quando este está no limite de deficiência de $\mathrm{Mg}$. A diferença entre os teores de $\mathrm{Mg}$ observados nas plantas pode estar relacionada também aos teores de Mg e à relação Ca:Mg no substrato, pois, segundo Lopes (1998) e Malavolta et al. (1997), quando a relação Ca:Mg se torna muito alta no meio de cultivo, as plantas podem absorver menos Mg. Afirmam, ainda, que, em plantas muito exigentes em $\mathrm{K}$, como é o caso dos citros, que exigem maior fertilização com este nutriente, se houver um teor absoluto de $\mathrm{Mg}$ relativamente baixo, os sintomas de carência magnesiana poderão aparecer se o quociente da relação $\mathrm{K}: \mathrm{Mg}$ for da ordem de 15 a 20. Considerando os teores foliares obtidos, as plantas dos sistemas 2 e 3 apresentaram um quociente da relação $\mathrm{K}: \mathrm{Mg}$ na ordem de 32 e 35 , respectivamente, e as plantas do sistema 1 obtiveram um quociente na ordem de 4 (Tabela 3 ).

Não foi observado efeito significativo das doses de adubo empregadas sobre os teores de Fe nas folhas, em nenhum dos sistemas. As plantas de limoeiro 'Cravo' cultivadas no sistema 1 apresentaram uma redução drástica no crescimento devido à deficiência de Fe, porém, a partir das pulverizações mensais com sulfato ferroso $\left(1,0 \mathrm{~g} \mathrm{~L}^{-1}\right)$, estas retornaram e mantiveram o crescimento ativo, apresentando folhas jovens sem manifestação dos sintomas. As plantas dos sistemas 2 e 3 não apresentaram sintomas de deficiência de $\mathrm{Fe}$, não necessitando de pulverizações corretivas. Observou-se que o substrato utilizado nestes sistemas de produção tinham, aproximadamente, três vezes mais teor de Fe do que o substrato comercial (Tabela 1).

No ponto de enxertia, os teores de Fe das plantas do sistema 1 foram superiores aos obtidos pelas plantas dos sistemas 2 e 3 (Tabela 3 ). Esses dados indicam que as pulverizações foram eficientes na correção da deficiência de Fe. Essa informação é interessante, uma vez que sintomas de deficiência desse nutriente têm sido observados em plantas cultivadas em vasos, como o cafeeiro (Pozza et al., 2000), com o uso de substratos comerciais à base de vermiculita e casca de pínus moída, e porque não existe recomendação de concentrações adequadas desse nutriente em adubações foliares para correção de deficiência em citros.

\section{CONCLUSÕES}

1) O efeito da adubação sobre os teores de nutrientes na matéria seca das folhas do limoeiro 'Cravo', no ponto de enxertia, foi influenciado pelo sistema utilizado na produção do porta-enxerto na fase de semeadura à repicagem.

2) As plantas provenientes do sistema de blocos prensados apresentaram, no ponto de enxertia, menores teores foliares de $\mathrm{P}, \mathrm{K} \mathrm{e} \mathrm{Fe}$, em relação às plantas provenientes de tubetes, mas apresentaram maiores médias de crescimento (peso seco do sistema radicular, peso seco de folhas, peso seco de caules e diâmetro do caule).

3) As plantas cultivadas nos sistemas onde foi utilizado o substrato composto por bagaço de cana + torta de filtro, apresentaram sintomas foliares de deficiência de $\mathrm{Mg}$ sem prejuízo ao crescimento que pudesse ser mensurado pelas técnicas utilizadas. Por outro lado, as plantas cultivadas no substrato comercial, composto de casca de pínus moída, apresentaram sintomas visuais de deficiência de Fe acompanhados de severa redução do crescimento.

\section{REFERÊNCIAS}

Barroso, D.G. Qualidade de mudas de Eucalyptus camaldulensis e Eucalyptus urophylla produzidas em tubetes e em blocos prensados com diferentes substratos. Tese (Doutorado em Produção Vegetal), Campos dos Goytacazes-RJ, Universidade Estadual do Norte Fluminense, UENF, 79p. 1999.

Carvalho, S.A. Propagação dos citros. Citricultura: Inovações tecnológicas. Informe Agropecuário, Belo Horizonte, v.22, n.209, p.21-25, 2001.

Leme, E. J. A. Uso e tratamento de resíduos agroindustriais no solo. In: Câmara, G.M.S; Oliveira, E.A.M. (Ed.) Produção de cana-de-açúcar. Piracicaba-SP: FEALQ, p.147-173. 1993.

Lopes, A.S. Manual internacional de fertilidade do solo (Tradução e adaptação). Piracicaba-SP, POTAFOS, 2. ed., 117p, 1998.

Malavolta, E.; Vitti, G.C.; Oliveira, S.A. Avaliação do estado nutricional de plantas: princípios e aplicações. 2. ed. Piracicaba-SP, POTAFOS, 319p. 1997.

Morgado, I.F., Resíduos agroindustriais prensados como substrato para 
a produção de mudas de Eucalyptus grandis Hill ex Maiden e Saccharum spp. Tese (Doutorado em Produção Vegetal), Campos dos Goytacazes-RJ, Universidade Estadual do Norte Fluminense, UENF, 102p. 1998.

Perin, J.R.; Carvalho, S.A.; Mattos Junior, D.; Cantarella, H. Efeitos de substratos e doses de fertilizante de liberação lenta no teor de clorofila e desenvolvimento vegetativo do limoeiro 'Cravo' em tubetes. Revista Laranja, Cordeirópolis-SP, v.20 (2): 457-462. 1999.

Pozza, A.A.A.; Guimarães, P.T.G.; Pozza, E.A.; Romaniello, M.M.; Silva, E.B. Desenvolvimento, nutrição e sanidade de mudas de cafeeiro em tubetes com diferentes substratos e fertilizações. In: I Simpósio de Pesquisa dos Cafés do Brasil, Poços de Caldas-MG: Anais...,
Ministério da Agricultura e Abastecimento, v.2, p. 1462-1465. 2000. Rezende, J.O.; Magalhães, A.F.J.; Shibata, R.T.; Rocha, E.S.; Fernandes, J.C.; Brandão, F.J.C.; Rezende, V.J.R.P. Citricultura nos solos coesos dos tabuleiros costeiros: análise e sugestões. Salvador-BA: SEAGRI/SPA, 2002.97p. (Série Estudos agrícolas; 3).

Sharma, G. C. Controlled-release fertilizers and horticultural applications. Scientia Horticulturae, Alabama, USA, v.11(2): 107-129. 1979.

Vichiato, M. Influência da fertilização do porta-enxerto tangerineira (Citrus reshni Hort. ex Tan. cv. Cleópatra) em tubetes, até a repicagem. 1996, 82f. Tese (Mestrado em Agronomia, área de concentração Fitotecnia) - Universidade Federal de Lavras, Lavras, 1996 